\title{
Assessment of costs, utilisation and user satisfaction of a mobile theatre unit over a 3-year period at a tertiary hospital
}

\author{
Eleanor Atkins^, Nadeem A. Mughal, Matthew Armon, Wissam Al-Jundi \\ Department of Vascular and Endovascular Surgery, Norfolk and Norwich University Hospital NHS Trust, Norwich, UK \\ Contributions: (I) Conception and design: W Al-Jundi, E Atkins; (II) Administrative support: M Armon, NA Mughal; (III) Provision of study \\ materials or patients: All authors; (IV) Collection and assembly of data: All authors; (V) Data analysis and interpretation: W Al-Jundi, E Atkins; (VI) \\ Manuscript writing: All authors; (VII) Final approval of manuscript: All authors. \\ Correspondence to: Mr. Wissam Al-Jundi. Norfolk and Norwich University Hospital NHS Trust, Colney Lane, Norwich NR4 7 UY, UK. \\ Email: Wissam.Al-Jundi@nnuh.nhs.uk.
}

\begin{abstract}
Background: A tertiary hospital installed a mobile laminar flow theatre and a mobile ward in 2015 to increase day-case capacity in the context of meeting expanded demand. Renting such mobile theatre units comes at a high cost. The utilisation and financial assessment of the mobile theatre unit is presented after 3 years of use.

Methods: Financials and utilisation of the unit were assessed. Structured interviews were carried out with staff members who work with the mobile theatre unit, as well as senior management at the hospital.

Results: In 3 years, 4,184 operations were performed, generating a total income of $£ 6$ million. Despite a considerable income, the first year showed an overall net loss, improving to net profit of £92,133 (profit margin $4.6 \%$ ) and $£ 254,875$ (12.5\%) in the second and third years respectively. Hand surgery comprised the bulk of procedures performed. Utilisation of the mobile theatre unit in 2019 was not significantly different from utilisation of the hospital's permanent Day Procedure Unit $(\mathrm{P}=0.239)$.

Conclusions: The mobile theatre unit business model is designed to provide a temporary solution to increase capacity for elective day case surgery. At our institution, the mobile theatre unit has successfully achieved its objective and covered its cost. Whilst long-term solutions must be found to increase elective and emergency surgical capacity to cope with demand, improvements in efficiency and utilisation of the mobile theatre unit can be made in the meantime.
\end{abstract}

Keywords: Operating theatre; day case; theatre productivity; theatre efficiency; clinical leadership; mobile theatre unit

Received: 10 June 2020; Accepted: 22 January 2021; Published: 25 December 2021.

doi: 10.21037/jhmhp-20-83

View this article at: http://dx.doi.org/10.21037/jhmhp-20-83

\section{Introduction}

The definition of day surgery in Great Britain and Ireland is a procedure that is performed when the patient is admitted, undergoes surgery and is discharged on the same day (1). There are several recognised benefits of this approach which include improved postoperative recovery, quick return to work, reduction in hospital acquired infections and venous thromboembolism (2). The wide range of day case procedures is expanding with increasing complexity and availability of minimally invasive techniques. The national target remains performance of $75 \%$ of elective surgery as day case (3). However, overall rates of day surgery remain variable across the UK (4). In addition, waiting lists for these procedures in many hospitals in the UK are usually

\footnotetext{
^ ORCID: 0000-0002-9455-6960.
} 


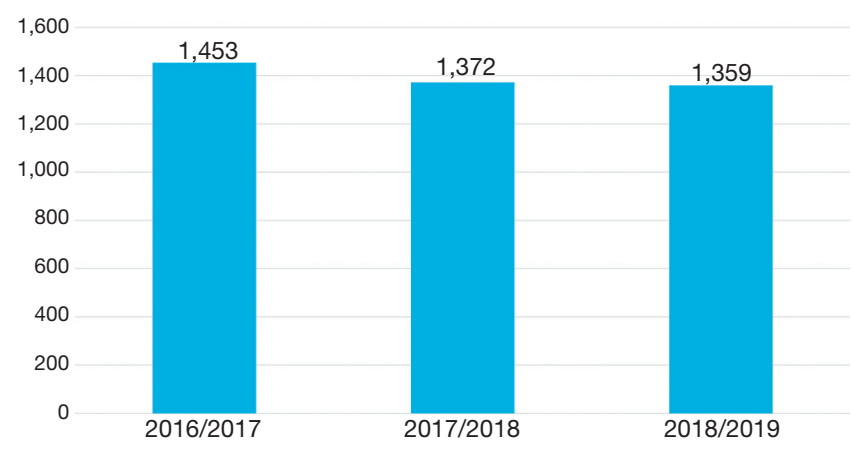

Figure 1 Mobile theatre unit total activity 2016-2019 (4,184 cases).

long due to mismatch between demand and availability of infrastructure including physical capacity and workforce. Norfolk and Norwich University Hospital (NNUH) is not an exception.

To cope with increasing demand for elective and emergency surgery, a mobile theatre unit was installed at NNUH in 2015 to increase day-case capacity and reduce waiting list times. It consisted of a single laminar flow theatre, an anaesthetic room, two recovery bays and a surgical ward. Theatre ancillary staff were included in the contract, which was for a minimum of 3 years with an aim of performing 100-120 extra day case procedures every month.

The aim of this study is to provide a strategic review of NNUH's investment in installing the mobile theatre unit. Assessment of clinical utility and financials along with feedback from internal users and senior managers are presented. We present the following article in accordance with the MDAR reporting checklist (available at http:// dx.doi.org/10.21037/jhmhp-20-83).

\section{Methods}

A review of monthly and annual total activity of the mobile unit was performed over the course of 3 financial years (2016-2019). Data was obtained from the management team at the Trust. Procedures were stratified per specialty and type of anaesthesia (local/regional anaesthesia versus general anaesthesia). Income was calculated accurately through obtaining operation codes and calculating the corresponding tariff of relevant cases. Reviewing the annual activity of the mobile unit offered the opportunity to accurately calculate the total cost of running the unit. This would equate to the cost of renting the unit (along with its accompanied workforce) on top of procedure related costs.
The latter was calculated based on patient level costing for each procedure and excluded surgeons' time. This was because most of the operating lists were incorporated within existing job plans and no additional cost was incurred.

\section{Statistical analysis}

Assessment of income and cost allowed for calculation of net profit/loss and profit margin. In addition, a review of theatre utilisation was performed, and a $t$-test was used to compare utilisation of mobile unit's to NNUH's existing Day Procedure Unit (DPU). Online GraphPad software was used for this statistical analysis. Clinical service assessment and internal user satisfaction were analysed through information gathered from structured interviews with four senior managers and 15 members of surgical teams at NNUH in order to assess challenges and possibilities.

\section{Results}

\section{Overall activity}

Over 3 years study period, 4,184 operations were performed in the mobile theatre unit (Figure 1). Analysis of utilisation for different specialties revealed that plastic surgery (predominantly skin lesion surgery and hand surgery) and trauma and orthopaedics (T\&O) (only hand surgery) were the most common users with combined $82 \%$ of cases belonging to these two specialties. General surgery (predominantly hernia surgery), vascular surgery (only endovenous ablation procedures for varicose veins) and oral surgery comprised another $14 \%$ while the rest of the specialties which registered utility of the unit performed few procedures (Figure 2). Analysis of specialty utilisation over time showed steady dominance of plastic surgery and T\&O over the study period (Figure 3). More procedures were performed under local or regional anaesthesia than general anaesthesia (Figure 4), and this was constant over the study period.

\section{Profit and loss}

Construction of the unit itself cost $£ 180,000$. In 3 years, total income generated from performing surgical procedures over the study period was just over $£ 6$ million (Figure 5).

The total cost of running the mobile theatre unit was calculated from the cost of renting the unit and its workforce, consumables, overheads and other costs over 


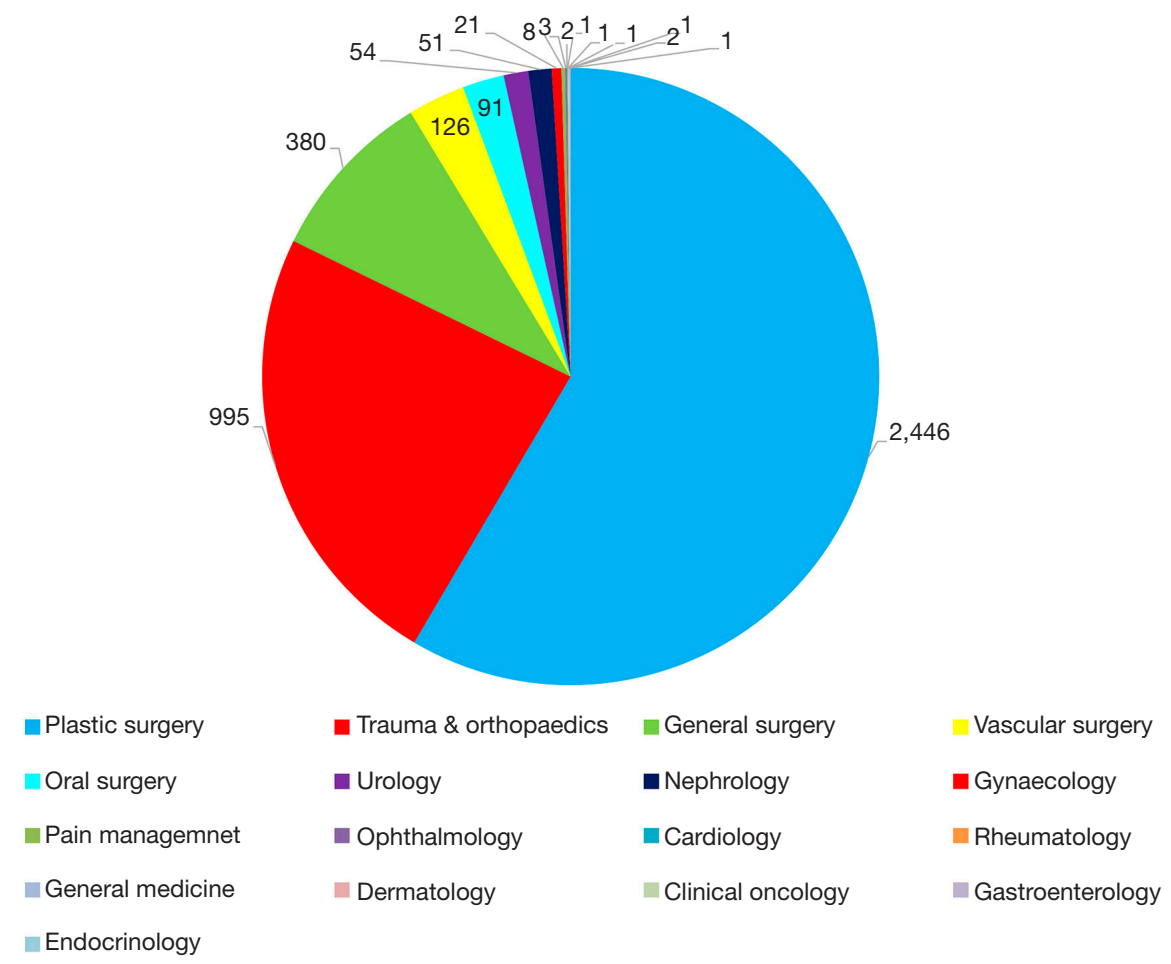

Figure 2 Number of cases performed at mobile theatre unit per specialty (2016-2019).

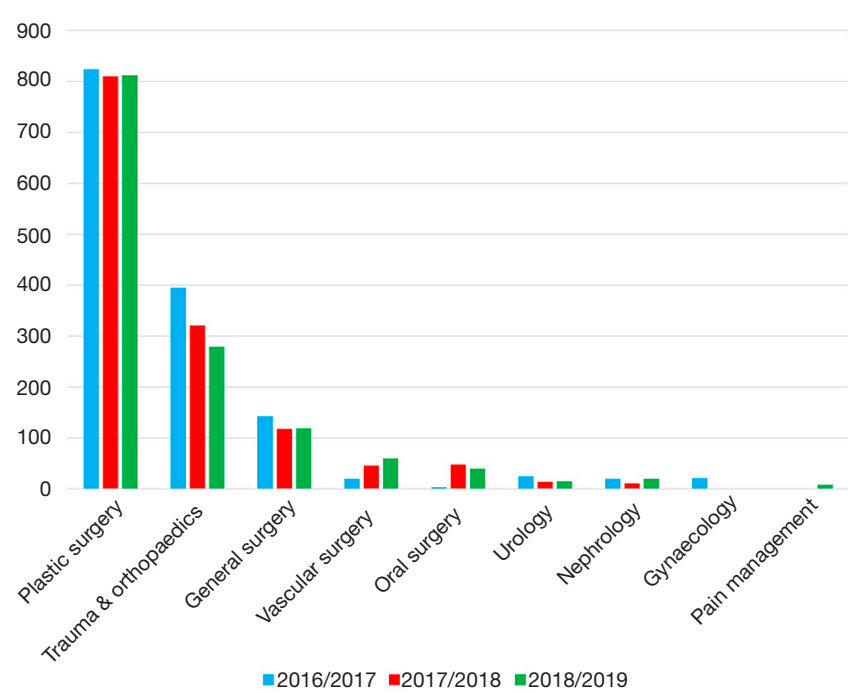

Figure 3 Number of cases performed per specialty over time (2016-2019).

the study period. This equated to $£ 5,661,402$ over the course of 3 years. Payments for hiring the mobile unit itself along with its related workforce comprised the bulk of the cost. Whilst the first year showed an overall loss of $£ 4,556$
$(-0.23 \%)$, net profit (profit margin) in the second year was $£ 92,133$ (4.6\%) and in the third year $£ 254,875$ (12.5\%) (Figure 6).

\section{Mobile unit utilisation}

The mobile theatre unit had an average utilisation of $71.5 \%$ (range, 64.7-80.8\%) in 2019 (Figure 7), with a relatively high percentage of booking opportunities remaining available. This is similar to the existing NNUH DPU, which has an average 2019 utilisation of $73.4 \%$ (range $69-79.4 \%$ ). There was no significant difference between the two $(\mathrm{P}=0.239)$.

\section{Feedback from internal users}

Structured interviews were conducted with senior managers and surgeons who utilise the mobile unit. Several strengths for having an independent onsite mobile day-case unit were identified. Outcomes from the interviews have been collated into an overall SWOT (Strengths, Weaknesses, Opportunities, Threats) analysis of the mobile theatre unit at NNUH, which is presented in Figure 8.

The mobile theatre unit provides an additional space 


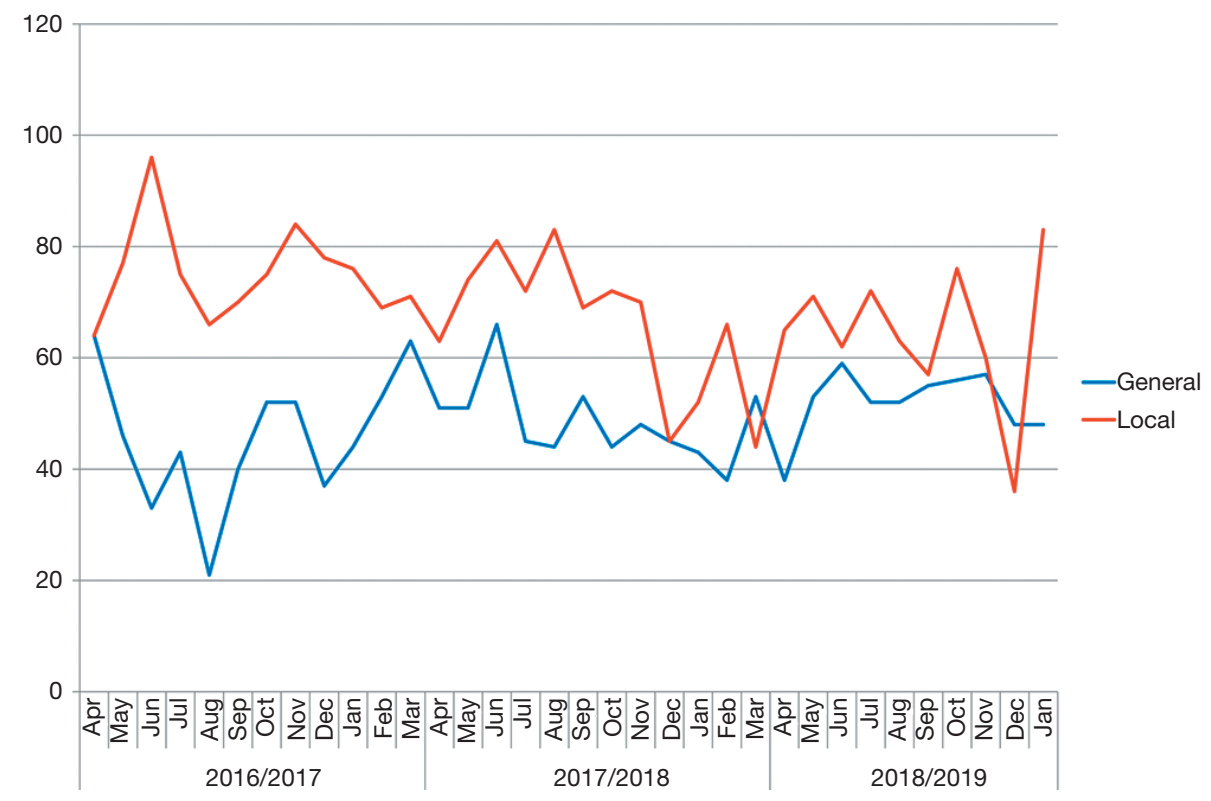

Figure 4 Number of cases performed at mobile theatre unit over time by type of anaesthetic.

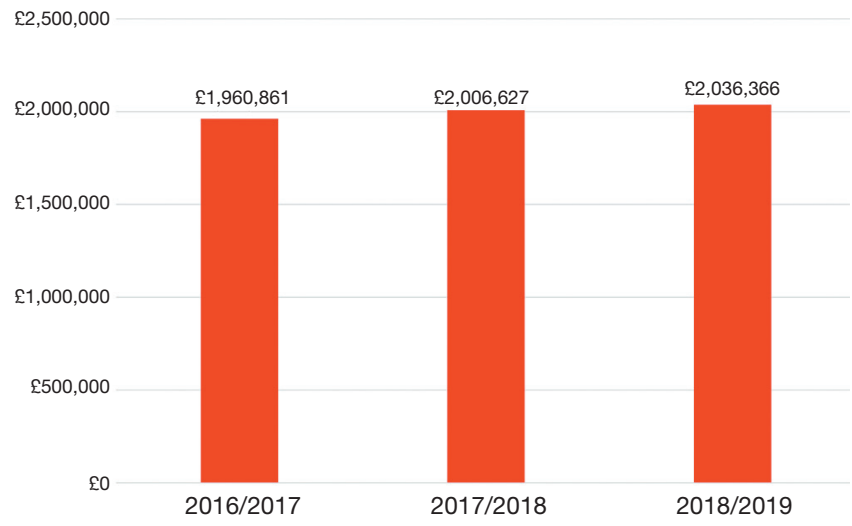

Figure 5 Total income of the mobile theatre unit 2016-2019 $(£ 6,003,854)$.

to perform day case procedures on site, an important advantage in that rapid access to emergency services is available if needed and expensive travel time for surgeons and other staff is eliminated. The unit also has a favourable cellular layout that reduces patient and staff movement throughout the perioperative processes.

Two important challenges that face NNUH are winter pressures and staff shortages. The unit is ring-fenced against bed escalation and the mobile unit company offers the option of providing workforce at additional cost. These advantages come at high monetary cost for rental and staff who might be untrained in specialised procedures.

Physical capacity in the mobile theatre complex is limited which can preclude performing certain procedures that require spacious operating theatres. Another criticism of the unit is its inability to offer bays for males and females simultaneously with resultant scatter of patients across different bays in DPU. This has a negative impact on patient flow and thus the unit's efficiency. Improvement of the above limitations can provide valuable opportunities to improve the utility, efficiency and profitability of the unit. However, there are important threats for its durability, namely, lack of buy in attitude from some clinicians due to perception of inferiority of the unit compared to hospital theatre complex, difficult financial climate and anticipated change in the way hospitals are reimbursed which will result in more emphasis on reducing cost rather than maximising service provision.

Interviews with internal users confirmed that there were no clinical concerns regarding outcomes of procedures performed at the mobile unit. However, it was recognised that all procedures performed were minor procedures or those associated with low risk of complications. On the other hand, there have been shortfalls in operational performance and efficiency due to multiple factors summarised within the SWOT analysis (Figure 8). 


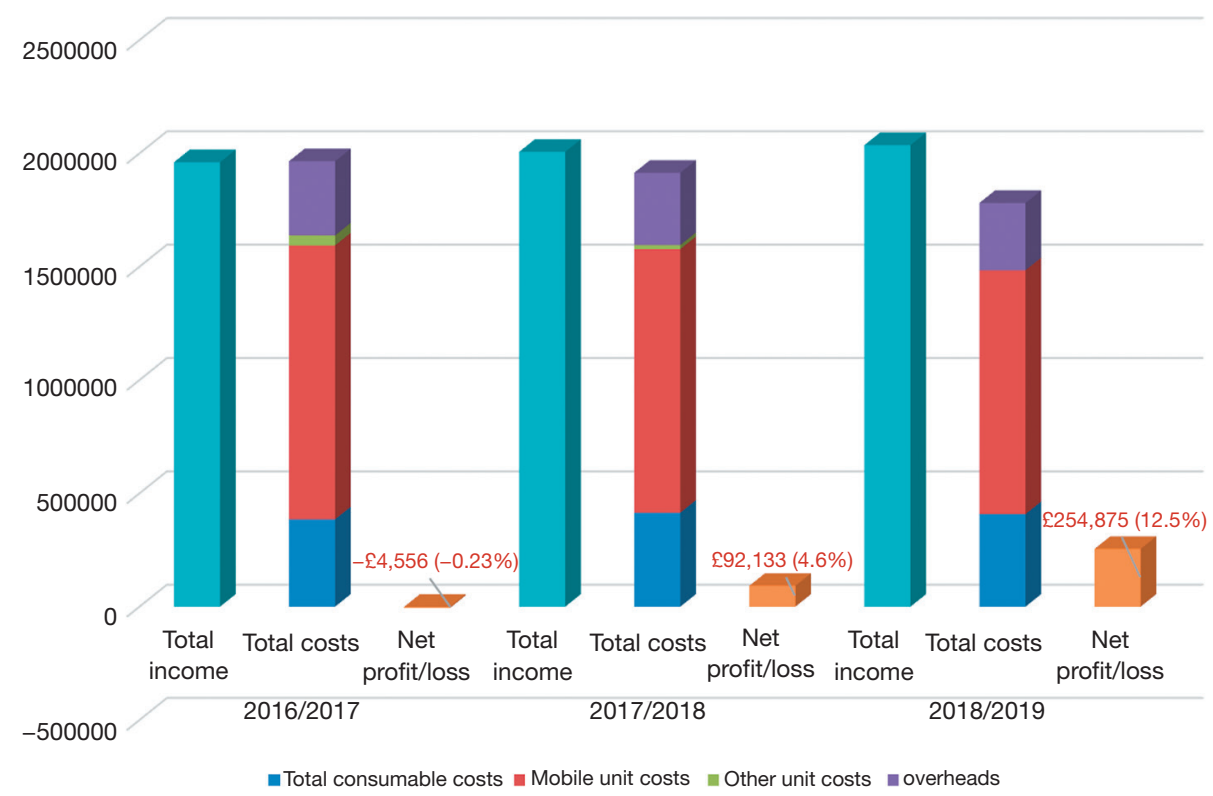

Figure 6 Net profit \& loss (profit margin) of the mobile theatre unit from 2016-2019.

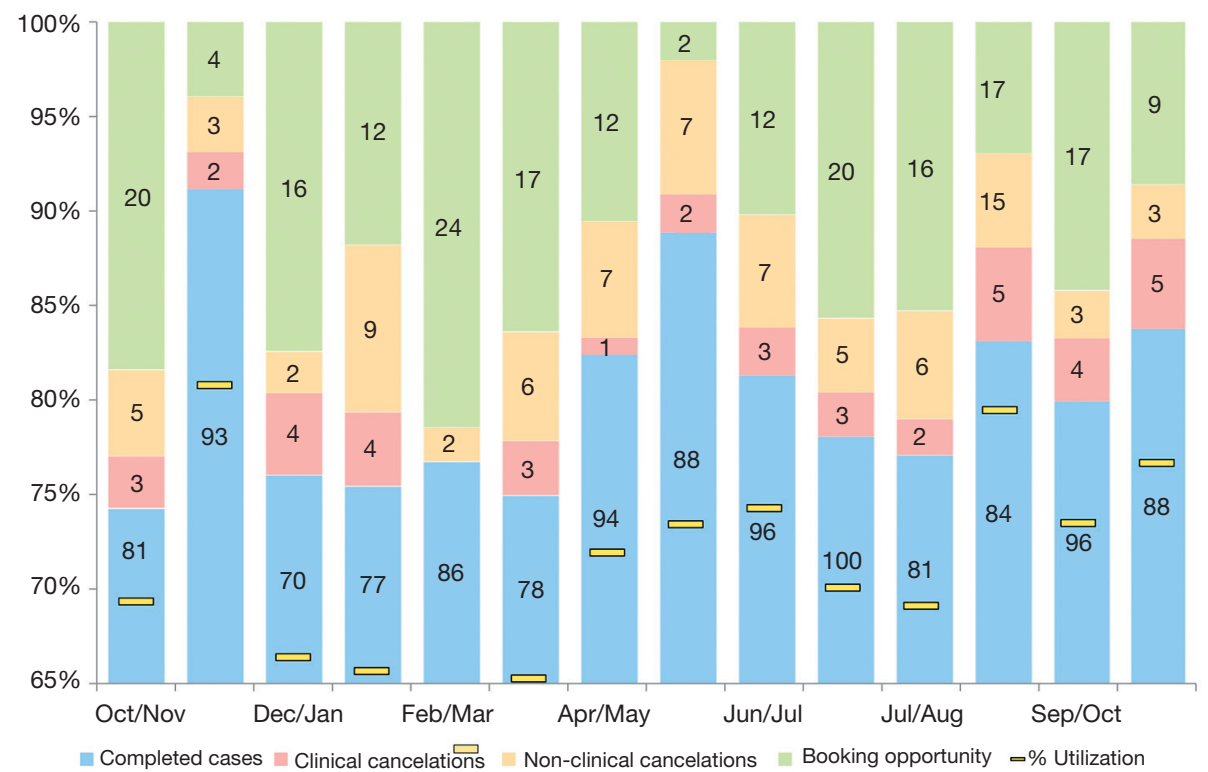

Figure 7 Mobile theatre unit utilisation rate in 2019 ranged from $65-81 \%$.

\section{Discussion}

\section{Summary}

This study provides a 3-year assessment of a mobile theatre unit at a tertiary hospital. Financial performance along with utilisation and users' feedback were analysed. The unit was initially installed to increase physical capacity of the hospital. Figure 1 confirms that it has delivered its clinical objective of performing an excess of 1,300-1,400 additional day case procedures per year. Despite a slight reduction of number of procedures performed per year with time, the income gained from the mobile theatre unit has increased, indicating more complex procedures with a higher patient level cost were performed (Figures 1,5). Net profit and profit 

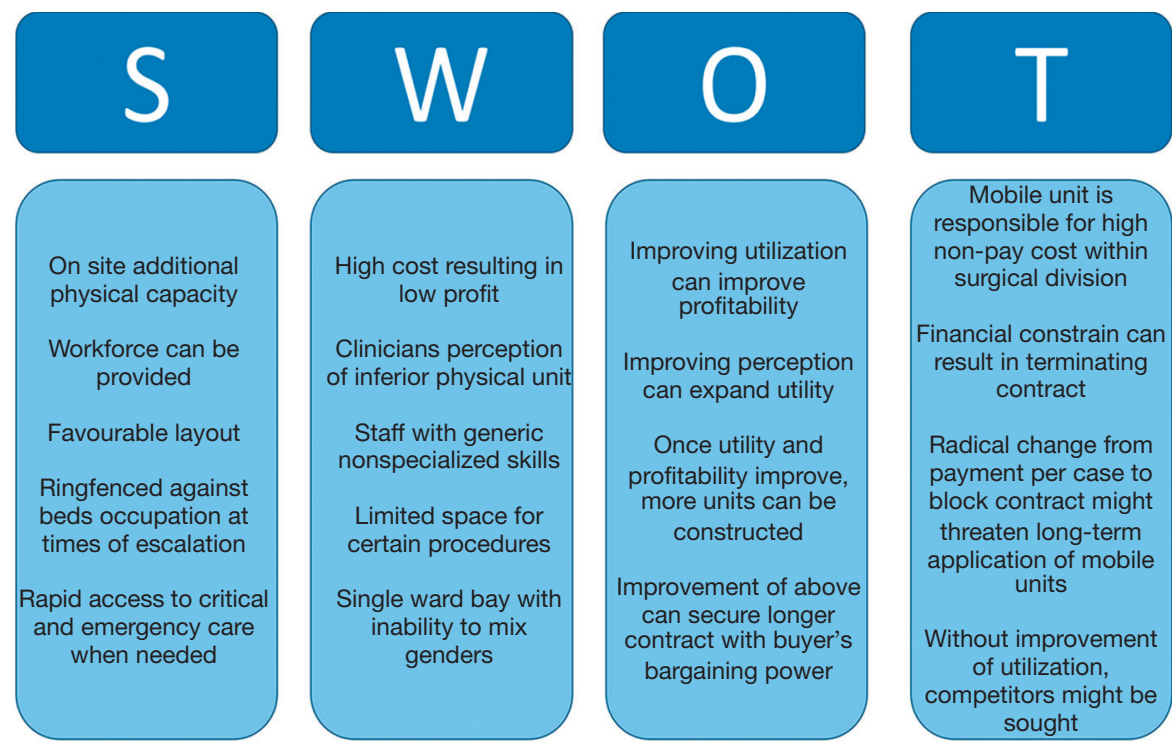

Figure 8 SWOT (Strengths, Weaknesses, Opportunities, Threats) analysis of mobile theatre unit.

margin have improved as well with time due to a reduction in costs, rather than a significant increase in activity. Use across different specialties and type of anaesthesia used has not changed markedly over the study period.

\section{Theatre utilisation and efficiency}

Theatre utilisation is a specific area that could be improved in order to further reduce cost, with a mean monthly utilisation of $71.5 \%$ in 2019 . Utilisation of the mobile theatre unit was not significantly different from the utilisation of the existing DPU in 2019, indicating that such improvements in efficiency can be made throughout the organisation. Improving efficiency is one way to improve profitability of the unit by enabling more procedures to be performed within the time available. The current utilisation of theatre space at NNUH is comparable to that reported in the literature (5), with the caveat that utilisation is heavily affected by case mix.

Interviews with internal users also revealed some reluctance to perform procedures that are considered relatively complex or involve prostheses. Evidence in the literature of the safety of such mobile theatre units for complex procedures is scarce. A 2017 study from Nottingham (6) assessed outcomes of lower limb arthroplasty procedures performed in mobile theatres. Despite the installation of laminar flow according to industry standards in the mobile units, surgeons noticed an increased rate of overall prosthetic infections in their practice. This was evident by a deep infection rate of 0 out of 684 procedures performed in main theatres compared to 8 out of 539 in mobile theatres $(1.5 \%)(\mathrm{P}=0.001)$. Patient groups were comparable in terms of risk factors, and the same theatre staff were operating across both settings. The authors concluded there was an unacceptable rate of deep infection in temporary operating theatres.

At NNUH during the study period, joint arthroplasties were not performed in the mobile unit. It was noted in the analysis above that Plastic and Orthopaedic surgeons remain the main users of the mobile unit ( $82 \%$ of cases) with the majority of cases being hand procedures. There were no clinical concerns raised from hand surgeons in relation to surgical outcomes. Indeed, a systematic review from Oxford University (7) was conducted to determine the incidence of infection for hand surgery in settings other than the operating theatre. In three studies there were no infections after surgery in an office, procedure room, or emergency department. Two studies reviewed 1,962 carpal tunnel decompressions and reported identical infection rates of $0.4 \%$. The authors concluded that some types of hand surgery can be performed outside the operating theatre without increasing the risk of infection. This is consistent with surgeon-reported clinical outcomes at our centre.

\section{Limitations}

The above study was not without limitations. The financial 
analysis excluded surgeons' time. Whilst in most cases this was accounted for in individual job plans, some of the procedures were performed under waiting list initiatives where an additional cost would be incurred. In addition, the way operating profits are calculated will change in the future, as the way hospitals are paid changes. Instead of payment by case or activity, block contracts will be implemented in which hospitals will be granted a fixed payment for a fixed number of procedures. This will effectively mean that emphasis will be more on reducing cost of running services rather than improving income. This is because the income will be fixed, while with the current model there is incentive to carry out more procedures to raise income. Finally, assessment of clinical outcomes was based on interviews with surgeons, while a review of patients' case notes and direct patient feedback were not sought. Nurses were not interviewed in the course of the study.

\section{Conclusions}

The NHS is witnessing an increase in demand for emergency and elective surgery, and installation of a mobile theatre unit acts as mitigation, increasing the capacity of our centre to provide day case procedures. Our experience demonstrates that renting such units along with its workforce is costly, but over the 3-year study period the unit provided sufficient activity to cover its cost. The mobile theatre unit business model is designed to provide a temporary solution for elective day case surgery. A long-term investment is required to extend elective day case capacity in a sustainable way. In the meantime, efficiency and productivity of the mobile theatre unit can be maximised as a short-term win to increase its activity. This in turn can help reduce waiting time for patients and maximise profitability for hospitals.

\section{Acknowledgments}

Funding: None.

\section{Footnote}

Reporting Checklist: The authors have completed the MDAR reporting checklist. Available at http://dx.doi.org/10.21037/ jhmhp-20-83

Data Sharing Statement: Available at http://dx.doi. org/10.21037/jhmhp-20-83

Conflicts of Interest: All authors have completed the ICMJE uniform disclosure form (available at http://dx.doi. org/10.21037/jhmhp-20-83). The authors have no conflicts of interest to declare.

Ethical Statement: The authors are accountable for all aspects of the work in ensuring that questions related to the accuracy or integrity of any part of the work are appropriately investigated and resolved.

Open Access Statement: This is an Open Access article distributed in accordance with the Creative Commons Attribution-NonCommercial-NoDerivs 4.0 International License (CC BY-NC-ND 4.0), which permits the noncommercial replication and distribution of the article with the strict proviso that no changes or edits are made and the original work is properly cited (including links to both the formal publication through the relevant DOI and the license). See: https://creativecommons.org/licenses/by-nc-nd/4.0/.

\section{References}

1. Association of Anaesthetists of Great Britain and Ireland; British Association of Day Surgery. Day case and short stay surgery: 2. Anaesthesia 2011;66:417-34.

2. Wang L, Baser O, Wells $\mathrm{P}$, et al. Benefit of early discharge among patients with low-risk pulmonary embolism. PLoS One 2017;12:e0185022.

3. Department of Health (2000). The NHS Plan: a plan for investment. A plan for reform. Available online: http://webarchive.nationalarchives.gov.uk/+/http://www. dh.gov.uk/en/Publicationsandstatistics/Publications/ PublicationsPolicyAndGuidance/DH_4002960 (accessed 05/05/2020).

4. Department of Health (2016). Operational productivity and performance in English NHS acute hospitals: Unwarranted variations. Available online: https://assets. publishing.service.gov.uk/government/uploads/system/ uploads/attachment_data/file/499229/Operational_ productivity_A.pdf (accessed 05/05/20)

5. Faiz $\mathrm{O}$, Tekkis $\mathrm{P}, \mathrm{McGuire} \mathrm{A}$, et al. Is theatre utilization a valid performance indicator for NHS operating theatres?. BMC Health Serv Res 2008;8:28.

6. Bloch BV, Shah A, Snape SE, et al. Primary hip and knee arthroplasty in a temporary operating theatre is associated with a significant increase in deep periprosthetic infection. 
Bone Joint J 2017;99-B:917-20.

7. Jagodzinski NA, Ibish S, Furniss D. Surgical site infection after hand surgery outside the operating

doi: $10.21037 /$ jhmhp-20-83

Cite this article as: Atkins E, Mughal NA, Armon M, Al-Jundi W. Assessment of costs, utilisation and user satisfaction of a mobile theatre unit over a 3 -year period at a tertiary hospital. J Hosp Manag Health Policy 2021;5:35. theatre: a systematic review. J Hand Surg Eur Vol 2017;42:289-94. 